\title{
A Case of Adult Onset Tic Disorder Following Carbon Monoxide Intoxication
}

\author{
Sang-Bae Ko, Tae-Beom Ahn, Jong-Min Kim, Yosik Kim, Beom S. Jeon
}

\begin{abstract}
Background: Adult onset tic disorders are usually secondary in origin. We report a case of adult onset tic disorder following carbon monoxide (CO) intoxication with typical magnetic resonance imaging features. Case Report: A 36-year-old woman developed temporarily suppressible patterned movements on her face, neck, and shoulder associated with sensory discomfort after CO poisoning. Magnetic resonance images showed bilateral symmetric cavitary changes in the globus pallidus. Clonazepam relieved much of her symptoms. Conclusion: Our patient developed a monosymptomatic tic disorder following CO intoxication. This further supports that altered outflow signals from the basal ganglia, especially the globus pallidus, may contribute to the development of tic disorders.
\end{abstract}

RÉSUMÉ: Un cas de tics chez un adulte après une intoxication à l'oxyde de carbone. Introduction: Les tics apparaissant chez l'adulte sont habituellement d'origine secondaire. Nous rapportons un cas de tics apparus chez une adulte suite à une intoxication à l'oxyde de carbone $(\mathrm{CO})$. À l'imagerie par résonance magnétique les lésions observées avaient un aspect typique. Observation: Des mouvements involontaires de la face, du cou et des épaules associés à une sensation d'inconfort sont apparus chez une femme âgée de 36 ans à la suite d'un empoisonnement par le CO. Ces mouvements étaient répétitifs et elle pouvait les supprimer temporairement. L'imagerie par résonance magnétique a montré des changements cavitaires symétriques bilatéraux dans le globus pallidus. Le clonazépam a soulagé la plupart de ses symptômes. Conclusion: Un trouble du mouvement monosymptomatique est apparu chez notre patiente à la suite d'une intoxication au CO. Des signaux efférents altérés provenant du noyau lenticulaire, du noyau caudé, de l'avant-mur et du noyau amygdalien contribuent probablement à l'apparition de tics.

Can. J. Neurol. Sci. 2004; 31: 268-270

Tics are sudden, purposeless, brief, jerky stereotyped movements or sounds and they are usually socially, occupationally and functionally disabling. ${ }^{1}$ Tic disorders are commonly considered to be childhood disorders. If the onset of the symptom is in adulthood, childhood tic experience should be questioned. ${ }^{2}$ If they are truly new ones, the secondary causes need to be considered. ${ }^{3}$

The common causes of secondary tic disorders are cerebrovascular disease, head injury, infection, drugs and toxins. ${ }^{4-6}$ There is only one case report of tic disorder caused by carbon monoxide (CO) poisoning in the literature. ${ }^{7}$ The patient was a 56-year-old man who was accidentally poisoned by $\mathrm{CO}$ in his winter cabin. He was comatose for several weeks. After recovering from coma, he had repetitive, stereotyped, irregular unvoluntary movements of his head. Brain computed tomography showed cortical atrophy, sulcal widening and enlargement of the ventricles with patchy low-density lesions in the basal ganglia. Tic disorder in this patient occurred in conjunction with diffuse encephalopathy.

Herein, we report a case of mono-symptomatic tic disorder, with typical magnetic resonance image (MRI) finding, caused by $\mathrm{CO}$ poisonings.

\section{Case Presentation}

A 36-year-old woman came to our hospital because of abnormal movements involving her right face, jaw, neck and right shoulder. She had been in good health until she suffered from CO poisoning at age 27. She was comatose for three days then recovered without neurologic deficit. Several weeks later, she developed an abnormal sensation of something stuck on her right face, neck, shoulder and scapular areas. This deep nagging sensation was partially relieved by facial contortion with mouth opening, lateral jaw motion, neck twisting and shoulder shrugging. The movements were quite patterned. Sensory ticks were absent. The movements were suppressible for a short time by volition, but escalating internal anxiety and discomfort forced her to resume.

From the Department of Neurology, and Clinical Research Institute, Seoul National University Hospital, BK-21 (S-BK, T-BA, J-MK); Neuroscience Research Institute of SNUMRC (BSJ); Seoul; Department of Neurology, Wonkwang University (YK), Iksan, Korea.

ReCEIVEd JANUARY 29, 2003. ACCEPTEDin FinALFORM November 17, 2003. Reprint requests to: Beom S. Jeon, Department of Neurology, Seoul National University Hospital, Yongon-dong 28, Chongno-gu, 110-744, Seoul, Korea 
Neurologic examination was normal except for repetitive stereotypic movements. Specifically, cognitive function was normal. Brain MRI, taken two months before this visit, showed bilateral symmetric high signal intensities on T2-weighted images and low signal intensities on T1-weighted images in the globus pallidus. This was felt to be cavitary necrosis, which is one of the typical radiological findings of $\mathrm{CO}$ poisoning (Figure). There was no abnormal gadolinium-GTPA enhancement. Clonazepam ( $0.5 \mathrm{mg}$ three times a day) relieved many of her symptoms. Pimozide ( $1 \mathrm{mg}$ three times a day) was added but it did not show any additive effect.

\section{Discussion}

The movement disorder in this patient is best classified as a tic. She had inner sensory discomfort, which was relieved by patterned movements which were temporarily suppressible. Escalating internal anxiety forced her to resume the movements.

While the repetitive nature of the movements may suggest stereotypy, mannerism, and perseveration, she had prominent sensory discomfort, and the movements were neither purposeless coordinate voluntary movements nor a goal directed behavior. Therefore, stereotypy, mannerism, and perseveration were unlikely.

Obsessive-compulsive disorders (OCD) may present as patterned movements with sensory components, and need to be differentiated from tic disorders. The movements of OCD are ritualistic and occur in response to obsessive ideas. However, the movements in our patient were performed without obsessive ideas and did not have any features of compulsive rituals. She felt the uncomfortable sensation and relieved the discomfort by movements. Therefore, OCD can be excluded.

Most of the movements in this patient were unsustained facial contortion with mouth opening, lateral jaw motion, neck twisting and shoulder shrugging. Some of the movements may have dystonic components. These components are best classified as a tic rather than dystonia because of prominent preceding sensory discomfort relieved by movement.

Among the neurologic complications after $\mathrm{CO}$ poisoning, reported movement disorders include parkinsonism, chorea, athetosis, ballism, myoclonus, tremor and dystonia..$^{8-11}$ There is only one case report of tic disorder following $\mathrm{CO}$ poisoning. ${ }^{7}$ In that case, the patient had repetitive, stereotyped, irregular movements of his head and could voluntarily abolish them. He also had evidence of diffuse encephalopathy with recent memory impairment, echolalia, pathologic laughter, and prominent grasp reflex. Brain computed tomography showed diffuse cortical atrophy and bilateral patchy low attenuation in the basal ganglia. ${ }^{7}$ Our patient has only motor tics without any associated neurologic symptoms and signs, and we suggest it represents a mono-symptomatic tic disorder following CO poisoning.

The differential diagnosis of bilateral globus pallidus lesions may include mitochondrial disease, metabolic disease, Wilson's disease, neurodegeneration with brain iron accumulation (previously termed Hallervoden-Spatz disease), accidental disulfiram ingestion, and surgical manipulation of the globus pallidus. ${ }^{12-16}$ Laboratory findings, MR signal characteristics and a negative history of drug ingestion or stereotactic surgery can exclude these alternative diagnoses.

The neuroanatomic basis of tic disorder is largely unknown, however, there is some evidence that the basal ganglia are involved in the development of tic disorders. Volumetric MRI studies have suggested that the normal asymmetry of the basal ganglia is lost in Tourette syndrome. ${ }^{17,18}{ }^{18} \mathrm{~F}$-fluorodeoxyglucose (FDG) positron emission tomography has shown evidence of decreased metabolic activity in the caudate and thalamic areas. ${ }^{19}$ Functional MRI showed decreased neuronal activity during periods of suppression in the ventral globus pallidus, putamen and thalamus. ${ }^{20}$

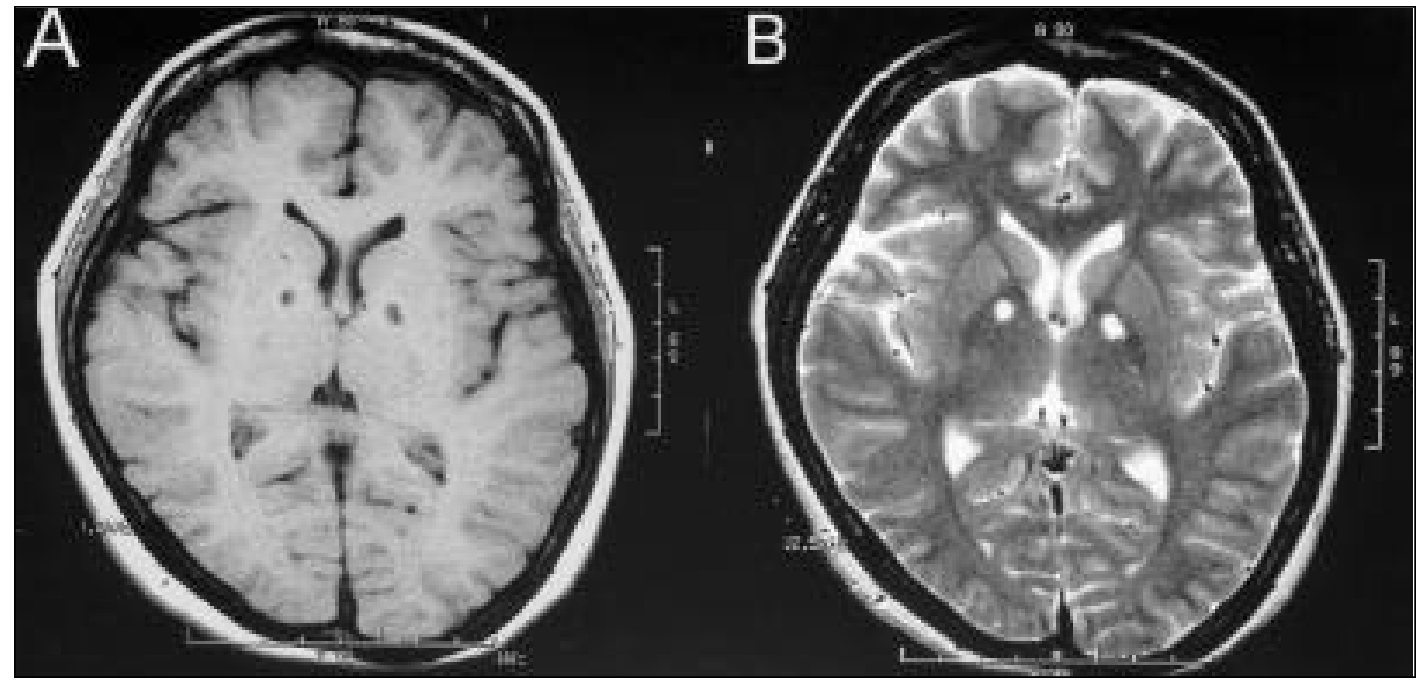

Figure: MRI of the patient. T1-weighted noncontrast image (A) shows low signal intensity in bilateral globus pallidus and T2-weighted $(B)$ image shows high signal intensity, which is compatible with cavitary necrosis following carbon monoxide (CO) poisoning. 
There is one report on the isolated involvement of the basal ganglia in tic disorders that suggests the role of basal ganglia and frontal cortical circuit in their pathogenesis. ${ }^{21}$ In our case, brain MRI revealed bilateral symmetric high signal intensities confined to the globus pallidus, indicating that altered outflow signals from the basal ganglia, especially globus pallidus, may contribute to the development of some tic disorders.

\section{REFERENCES}

1. Roger MK. Tourette's syndrome. In: Ray LW, William CK, (Eds). Movement Disorders; Neurologic Principles and Practice. New York: McGraw-Hill 1997: 569-575.

2. Jankovic J. Phenomenology and classification of tics. Neurol Clin 1997; 15:267-275.

3. Sylvain C, Blair F. Adult onset tic disorders. J Neurol Neurosurg Psychiatry 2000;68:738-743.

4. Yochelson MR, David RG. New-onset tic disorder following acute hemorrhage of an arteriovenous malformation. J Child Neurol 2000;15:769-771.

5. Alegre S, Chacon J, Redondo L, Navarro-Busto C, Solana B. Posttraumatic tics. Rev Neurol 1996;24:1280-1282.

6. Kumar R, Lang AE. Tourette syndrome. Secondary tic disorders. Neurologic Clin 1997;15:309-331.

7. Pulst SM, Walshe TM, Romero JA. Carbon monoxide poisoning with features of Gilles de la Tourette's syndrome. Arch Neurol 1983;40:443-444.

8. Klawans HL, Stein RW, Tanner CM, Goetz CG. A pure parkinsonian syndrome following acute carbon monoxide intoxication. Arch Neurol 1982;39:302-304.

9. Davous P, Rondot P, Marion MH, Gueguen B. Severe chorea after acute carbon monoxide poisoning. J Neurol Neurosurg Psychiatry 1986;49:206-208.

10. Schwarz A, Hennerici M, Wegener OH. Delayed choreoathetosis following acute carbon monoxide poisoning. Neurology 1985;35:98-99.

11. Choi IS. Carbon monoxide poisoning: systemic manifestation and complication. J Korean Med Sci 2001;16:253-261.

12. Mesiwala AH, Loeser JD. Bilateral globus pallidus infarction secondary to disulfiram ingestion. Pediatr Neurosurg 2001;34:224.

13. van Wassenaer-van Hall HN, van den Heuvel AG, Algra A, Hoogenraad TU, Mali WP. Wilson disease: findings at MR imaging and CTof the brain with clinical correlation. Radiology 1996;198:531-536.

14. Martinez BA, Arcas J, Roche MC, et al. Bilateral hypodensity of the basal ganglia. Clinico-evolutionary correlation in children. Rev Neurol 2001;33:101-111.

15. Abosch A, Lozano A. Stereotactic neurosurgery for movement disorders. Can J Neurol Sci 2003;30(Suppl 1):S72-S82.

16. Kessler C, Schwechheimer K, Reuther R, Born JA. HallervordenSpatz syndrome restricted to the pallidal nuclei. J Neurol 1984;231:112-116.

17. Peterson BS, Riddle MA, Cohen DJ, et al. Reduced basal ganglia volumes in Tourette's syndrome using three-dimensional reconstruction techniques from magnetic resonance images. Neurology 1993;43:941-949.

18. Singer H, Reiss A, Brown J, et al. Volumetric MRI changes in basal ganglia of children with Tourette's syndrome. Neurology 1993;43:950-956.

19. Eidelberg D, Moeller JR, Antonini A, et al. The metabolic anatomy of Tourette's syndrome. Neurology 1997;48:927-934.

20. Peterson BS. Neuroimaging studies of Tourette syndrome: a decade of progress. In: Cohen DJ, Jankovic J, Goetz CG, (Eds). Tourette Syndrome. Advances in Neurology Vol 85. Philadelphia: Lippincott Williams \& Wilkins, 2001;179-196.

21. Demirkol A, Erdem H, Inan L, Yigit A, Guney M. Bilateral globus pallidus lesions in a patient with Tourette syndome and related disorders. Biol Psychiatry 1999:15:863-867. 